\title{
TEKOÁ PYAÚ: A BUSCA DA MORADA CELESTE GUARANI MBYÁ DA AMAZÔNIA MERIDIONAL ${ }^{1}$
}

\author{
ALMIRES MARTINS MACHADO \\ INBRAPI \\ ROSALVO IVARRA ORTIZ \\ $U F G D$
}

\begin{abstract}
RESUMO: $O$ presente estudo procura analisar, sob as óticas histórica e antropológica, a maneira como as lideranças religiosas Mbyá Guarani da região amazônica paraense cumprem os sonhos recebidos de Nhanderú Ete, iniciando a caminhada em direção a terra sem mal, a Yvy Marãe"y; assim retornam ao local de ocupação antiga ou a indicada por Nhanderú, terra com a qual mantêm laços históricos de luta. Portanto, a pesquisa versa sobre o modo como "escolhem", "adotam," "retomam," ressignificam, reterritorializam, guaranizam a terra onde pausaram a caminhada.
\end{abstract}

PALAVRAS-CHAVE: Guarani; cosmologia; territorialidade.

ABSTRACT: The present study seeks to analyze, from a historical and anthropological perspectives, the way in which the Mbya Guarani religious leaders of the Amazonian region of Pará state, Brasil, fulfill the dreams received from Nhanderú Ete, beginning the journey towards the land without evil, so they return to the place of old occupation or indicated by Nhanderu, land with which they maintain historical ties of struggle. Therefore, the research deals with the way they "choose", "adopt," "resume," re-signify, reterritorialize, Guaranize the land where their paths have paused.

\footnotetext{
${ }^{1}$ Originalmente apresentado como tese de Doutorado em Antropologia- PPGA/UFPA pelo primeiro autor e, posteriormente, modificado com novos dados apresentados pelo segundo autor, que por sua vez realiza pesquisa com outro grupo Guarani- os Nhandevá de Mato Grosso do Sul.

3 Graduado em Direito pelo Centro Universitário da Grande Dourados (UNIGRAN, 2004), Mestrado em Direitos Humanos pela Universidade Federal do Pará (UFPA), 2009. Doutor em Antropologia pela Universidade Federal do Pará (UFPA), 2015. Membro do Núcleo Jurídico do Instituto Indígena Brasileiro para a Propriedade Intelectual (INBRAPI). Pertencente à etnia Guarani e Terena. E-mail: ateguara@gmail.com.

4 Possui graduação em Licenciatura plena em Ciências Sociais pela Faculdade de Ciências Humanas da Universidade Federal da Grande Dourados - FCH/UFGD. Atualmente é acadêmico do Mestrado em Antropologia Sociocultural (linha de pesquisa: arqueologia, etno-história e patrimônio cultural) pela mesma instituição de ensino, com início em 2017. É membro do grupo de pesquisa do Conselho Nacional de Desenvolvimento Científico e Tecnológico (CNPQ), GIPEDAS - "Grupo Iberoamericano para Pesquisa e Difusão da Antropologia Sócio-Cultural". Possui artigos publicados no Brasil e na Europa. Filho de indígena Guarani. Pesquisa arte, memória e cosmologia guarani em Mato Grosso do Sul. Bolsista: FUNDECT/MS. E-mail: rosalvortiz@ hotmail.com.
} 
KEYWORDS: Guarani; land without evil; territoriality.

Para sempre serei jardineiro, só para cuidar da flor mais bela que há no universo: você. Para sempre serei beija-flor, só para sobrevoar e sentir o aroma da flor mais perfumada que há: você. Para sempre serei estrela guia para guiar-te pela imensidão do tempo e do espaço. Carregar-te nos braços no labirinto da vida. Contigo eu quero navegar por todos os oceanos... Os seus braços é o melhor lugar do mundo para repousar e recomeçar (Rosalvo Ivarra Ortiz).

\section{Iniciando a discussão}

Segundo Branislava Susnik (1980, p. 9), no século XVI, quando se iniciou a conquista da América por portugueses e espanhóis, os Guarani encontravam-se em uma área compreendida entre os rios Paraguai, Paraná, Tietê, Uruguai e Jacuí, e alguns assentamentos no litoral Atlântico. Conforme Monteiro (1998, p. 476-477), do Chaco até o Atlântico, das capitanias do sul até o Rio da Prata, a presença guarani abrangia, no século XVI, uma área que corresponde hoje aos estados brasileiros do Rio Grande do Sul, Santa Catarina, Paraná, São Paulo e Mato Grosso do Sul, e ainda partes dos países vizinhos, entre os principais rios do sistema Paraná-Paraguai.

Os deslocamentos guarani aconteciam em primeiro lugar por buscarem uma terra sem mal, do bem viver, ou seja, encontrar a salvação dos principais males do universo. Alguns grupos desciam em direção ao nascente, outros seguiam para o norte ou oeste. Cada grupo com seu nhanderú (orientador espiritual); este, por sua vez, guiado pelos sonhos e visões recebidos de Nhanderú Vussu (nosso deus maior). Caminhava-se por meses, anos, na esperança de chegar à terra sem mal, terra onde se viveria para sempre.

Há que se diferenciar os três tipos de yvy marãe'y (terra sem mal) buscada na caminhada, que são complementares:

O primeiro é celeste, espiritual, em que não se morre mais, o paraíso que o Guarani esperava encontrar atravessando o mar, terra essa descrita nas narrativas de criação, onde a flecha encontra a caça sozinha, a roça ao ser plantada imediatamente germina, nasce, cresce e produz ao fim do dia; lá não há doenças, guerras, somente paz, é o lugar da imortalidade. É o teko ambá (aldeia celeste). Pode ser alcançada também quando, ao dançar e cantar à exaustão, se chega ao estado de aguyje (iluminação). O mesmo pode ocorrer ainda em vida: para tanto, é preciso cantar, dançar, ficar com alma e corpo leve, consumir alimentos 
estritamente prescritos para tal, ademais, é preciso estar num local onde se possa exercitar o bom viver. Aqui o foco está em exercer o direito de alcançar, adentrar e estar na aldeia celeste, enquanto ser divinizado, em razão de ter praticado os desígnios do modo de vida guarani, por meio da orientação religiosa prescritos por Nhanderú Tenonde (nosso pai primeiro), cotidianamente lembrados e ensinados pelo nhanderú (nosso pai) terreno, seja na casa especificamente construída para tal ou em qualquer lugar da táva (aldeia) ou do território.

O segundo tipo de terra procurada é aquele onde é possível exercitar o teko porã (maneira boa de viver), não importando onde se localize, desde que sejam percebidas as características de uma terra frutífera, com boas águas, nascentes, terra boa para plantar roças, caça em abundância, floresta fechada com boas madeiras, de preferência, à beira mar (no entanto, não era regra); essa é a terra primordialmente ecológica.

A terceira terra é aquela terra onde a caminhada permitia chegar; ela poderia e pode ser guaranizada, ressignificada, re-territorializada, curada por meio dos rituais nos quais se estabelece o vínculo dos humanos com os não humanos do lugar. Formata-se uma identidade, pertencimento e parentesco com todos que também ocupam aquele espaço (jaras). A partir de então, o Guarani passa a ser parte do lugar, plantando as roças e construindo as casas e a opy (casa onde se ensina os princípios do modo de vida guarani) para as cerimônias, dando continuidade ao seu modo de ser religioso.

\section{A primeira terra}

Vivendo nessa terra, se alcança a yvy tenonde (primeira terra), o paraíso tão sonhado e almejado. Neste espaço, dão continuidade à forma de vida coletiva, bem como às práticas culturais que os distinguem, identificando-os como Guarani, sua tradição, e a terra é tradicionalmente ocupada e explorada. Para o Guarani, a terra é mais que um pedaço de chão com a sua megasociobiodiversidade, é um ente com vida, espírito, alma, em cujas entranhas se escrevem a gênese guarani enquanto ser humano e com a qual mantém um vínculo holístico.

É a terra que permite a perpetuação do seu modo de vida, ela é responsável por sua sobrevivência, é considerada mãe, irmã, solo sagrado, sem a qual é impossível continuar reproduzindo o seu modo de vida e existir como povo distinto. Aqui a intenção é prolongar o máximo possível o bom viver, gozar a vida boa, praticando a reciprocidade, religiosidade, solidariedade e o mboraiú (amor) guarani, pilares da socialidade no tekoá (lugar de morar).

O segundo motivo dos deslocamentos era fugir das bandeiras, do aprisionamento, de ser feito escravo, de perder a liberdade. Razão de adentrarem cada vez mais as matas ou as terras antes não ocupadas que, em alguns casos, não faziam parte de seu território. Esses grupos 
Guarani, acossados, caçados, não aceitaram a cruz (viver junto aos religiosos); por outro lado, temiam as espadas espanholas e portuguesas, pois carregavam consigo as marcas dos enfrentamentos. Assim iniciavam a caminhada em busca de nova terra.

Muito antes da Guerra do Paraguai, alguns grupos Guarani viramse forçados a fugir das hostilidades, buscando uma terra de paz, especialmente os do sudoeste paraguaio. Grupos de Mbyá, Guarani e Kaiowá se puseram a caminhar em busca de um local que pudessem transformar em seu tekoá, do seu guarã.

Dentre esses grupos que iniciaram a grande caminhada, alguns foram para o litoral paulista, outros se dirigiram para partes do que é hoje o estado de Mato Grosso do Sul, e um dos grupos chegou ao estado do Pará, hoje estabelecidos no município de Rondom do Pará, nominando-o Tekoá Pyaú. Quando os Guarani Mbyá que lá se encontram iniciaram o processo de caminhada rumo a yvy ju (terra da luz), também conhecida como yvy marãe'y (terra sem mal), somavam em torno de 25 famílias mbyá nos relatos dos mais velhos, que saíram da Argentina rumo a Belém, nome esse que foi revelado por meio de sonhos ao nhanderú/opyguá Karaí Mirim (Manoel Rodrigues), e por estes guiados na caminhada. A data da partida do grupo é incerta: alguns datam entre os anos de 1900 e 1920.

Considerar esse grupo mbyá como sendo apenas mais um que caminhou em busca de um local seguro seria uma irresponsabilidade de nossa parte, estaria desconsiderando a especificidade do grupo, assim como sua reação frente à pressão e opressão sofrida perante as frentes de expansão do chamado "desenvolvimento", ao anti-indigenismo e aos resíduos da cultura juruá (branco).

\section{Avó Benedita e o início da caminhada celeste}

No relato da jary’ì (avó) Benedita, nascida em 1923 em Goiás, ela afirma que foram seus pais que se puseram a caminhar, guiando o grupo. O local, provavelmente, foi nas regiões de morada dos antigos Cainguá ou Ka'guá (pertencentes à floresta, povo da floresta), que, de acordo com o Velho Zé (83 anos), saíram de uma região distante, que ele afirma ser entre Argentina e Paraguai, possivelmente a atual região de Missiones. Lembra que sua avó Ihe contava que em algum lugar no Paraguai, algumas famílias se separaram do grupo maior e foram em direção ao sol nascente, rumo a São Paulo; segundo afirma, a intenção era chegar ao mar por outro caminho. O cacique Werá narra a forma como se dava a caminhada :

Viajava pelo mato, parava, prantava, colhe e depois volta caminhá. Eu natxi no Goias Velho, Campo Alegre, onde o notxio (nosso) grupo trabalhou uns quatro anos e pegaram a caminhá. Pra caminha os velhos usavam py'á, feito de coro de mboré (anta) e vaca; enrolava no 
pé até no djoeio e coturava. O txol (sol) era muito quente, areia quente, piçarra quente no caminho. Txegamos no rio pequeno e cometxaram a trabaiá na fadjenda e de tardinha ia no rio pega petxe de timbó, pegava muito petxe que até perdia. Depois foi pra Jutxara (Jussara), vila pequinininha, poquinha djente, atxo que oito (08) cadja (casa), mais ou menos. Dali caminhou para Santa Rita e dipois Modjarlandia (Mozarlandia), poquinha dgente, dez cadja (casa), mais txamava barreirinho antes. Foi aí que pegaram doentxa do Juruá, os mais velhos morreu muito, uns vinte. Lá morreu o capitão Manoel e aí deu sarambi (esparramar), cada um foi pra um lado (fala de WERÁ, em 2015).

Os relatos dos integrantes mais velhos da comunidade e do cacique Werá (79 anos) sobre o processo do Oguatá e de estabelecimento em Rondom do Pará, e o atual tekoá (lugar de morada), é uma forma de se orientarem e demonstrarem o modo de vida antigo que necessita ser rememorado, revivido, potencializado, "preservado". A memória é o meio pelo qual as narrativas se alimentam, procuram assoprar as cinzas do esquecimento que estão por sobre as brasas vivas dos acontecimentos de ontem, para servir ao presente e ao futuro. Assim, as narrativas se delineiam a partir da projeção de um futuro que necessita retornar e aprender com o passado não tão distante, que precisa buscar a manutenção do que é considerado ser a essência mbyá, pois segui-la é estar mais próximo dos desígnios de Nhanderú Ete (deus verdadeiro) e de alcançar a yvy ju (terra dourada).

Nesse sentido, a comunidade hoje passa por um processo de rearticulação dessas memórias e encontra, no ensinamento dos mesmos aos mais jovens, meio de preservar sua cultura, permitindo que filhos e netos possam desfrutar futuramente de uma vida boa, com qualidade, a fim de que elementos do passado sejam retomados e ressignificados no presente, na guaranização do tekoá. O anseio dos integrantes da comunidade por produzir vídeos e CDs, registrando suas práticas culturais, assim como o desejo de que a história do grupo seja escrita, demonstra como esses novos elementos midiáticos constituem importantes ferramentas para a preservação cultural (ainda que não vivos) e para o fortalecimento espiritual do grupo. Nesse sentido é a fala do velho Zés:

Os mais véios mal falava a linguagem de juruá, fui fala com uns 15 [quinze] anos, agora eu fala com brancos. Odje o crianxinha dja natxe [nasce] falando a linguagem do juruá e esquetxendo a notxia linguagem, aos poco ta acabando tudo, ta misturando tudo. Eu fica no lugar do

\footnotetext{
${ }^{5} \mathrm{O}$ velho Zé, nosso interlocutor, ama uma boa conversa, contar sonhos, narrar o Oguata, dar conselhos e tomar o ka'á'y (chimarrão).
} 
Raimundo, depois que ele morre, eu contadô de istória eu, mais ninguém mais que larga TV e me escutá, eu já ta velho muito e Xe Endu [meu ouvir], djá não é bom mais, escuta poco. É por itxo [isso] que eu venho no teu cadja [casa] todo dia cedo, tu escuta minha istória.

Dessa forma, se perscruta a importância da memória sobre a caminhada, o modo de vida dos tujá (velhos, idosos), para o processo de afirmação cultural, identitária, e as estratégias políticas para garantir que seu modo de vida cultural, material, econômico e cosmológico seja assegurado, rearticulado a partir da utilização de diferentes meios para conectar o passado e as práticas tradicionais ao presente. Alguns dos rituais e práticas ainda são mantidos na comunidade, a vida de seus integrantes alia-se à necessidade de estarem mais próximos dos desígnios de Nhanderú Ete (nosso deus verdadeiro). Agir diferente significa permitir que as forças representantes do mal se aproximem e se apossem do corpo e da alma do indivíduo transgressor do modo correto de se viver, mesmo depois da morte.

Conhecidos outrora como teólogos da floresta (CADOGAN, 1959), os Guarani incorporam em todo o seu cotidiano práticas relacionadas à veneração e respeito a Nhanderú Ete. Observam hábitos alimentares (não comer à noite, na estrada ou na mata), procuram inserir em sua dieta alimentos tradicionais, rejeitam a preguiça, observam a proibição de relações sexuais com mais de um parceiro e procuram participar assiduamente das reuniões na opy (casa ritual).

O modo de vida do Guarani é sempre pautado por orientação religiosa: ainda hoje persiste o pensamento sobre o modo de ser religioso, a prática é que está perdendo frequência. Apesar de todas as influências, continua-se acreditando na terra em que não se morre mais, ou a terra madura, yvy ju - o porém é que se está sem orientador religioso. Talvez o Guarani continue teólogo, mas sem floresta, sem a terra de seus anseios. As viagens terrenas e espirituais são uma constante: nessas idas e vindas ao mundo espiritual, pode ocorrer de haver sonhos indicando que chegou o momento de retomar a caminhada. Nhanderú (nosso pai) envia os sonhos e confirma a muitos que é chegada a hora de voltar para a terra dos pais e retomar os rituais nos lugares sagrados ou consagrados.

\section{$O$ relato do Velho Zé}

Segundo o relato do Velho Zé, os caminhantes guarani nunca passavam por cidades e, considerando os lugares nominados nas conversas pelo mesmo e pela jary’i (avó) Benedita, foi possível traçar a rota no mapa dos lugares por onde passaram, desde Missiones, na Argentina, até Rondom do Pará, no Brasil, embora esse traçado seja considerado a partir da entrada no Brasil, pois não há na memória dos 
mesmos nomes de locais por onde passaram via Paraguai. O Velho Zé conta que, em cada lugar em que montavam acampamento, ficavam cerca de dois a três anos, trabalhando nas fazendas. Mas se o fazendeiro era "bom", eles trabalhavam por mais tempo, poupavam dinheiro para seguir viagem, ficavam até cinco anos na mesma fazenda e, nesse período, estudavam a geografia do lugar.

O primeiro lugar presente em suas memórias é o Rio Piraty, no Paraguai, que fazia fronteira com Mato Grosso. Passaram por Ponta Porã, caminharam até chegarem ao Rio Coxim. Ficaram por um tempo nas fazendas de Campo Alegre e da Pedra. Adentraram o estado de Goiás pelo município de Jussara. Alcançaram a cabeceira do Rio Araguaia, na cidade de Santa Rita do Araguaia, Goiás. Pelo contato com a população local, uma doença vitimou muitos deles, no município de Mozarlândia (GO), no ano de 1959, segundo afirmam. Entre as vitimas se encontrava o nhanderú (nosso pai) Karaí Mirim (Manoel Rodrigues), e a partir daí que, sem o orientador espiritual, o grupo viveu momentos de incerteza, sem saber por qual caminho seguir, como na narrativa dos gêmeos. Então, por volta do ano de 1966, prosseguiram para Cocalina, às margens do Araguaia. Nesse local houve uma cisão, as famílias dividiram-se em três grupos.

Segundo Werá Guarani, sua avó liderou um grupo que seguiu na frente. Posteriormente, o restante de sua família, juntamente com duas outras, prosseguiu viagem por São Miguel do Araguaia, indo para a Ilha do Bananal de canoa, descendo o Rio Araguaia. Durante o percurso, de mais ou menos três meses, eles comiam carne de caça, tartaruga e melancia que encontravam na beira do rio. No entanto, quando chegaram à Ilha, descobriram que o grupo da jary’ì (avó) de João tinha ido para Porto Nacional. Decidiram então encontrá-los.

Em 1969, saíram da Ilha do Bananal de avião, depois de dois anos de trabalho, dirigindo-se para Porto Nacional, no atual estado de Tocantins, onde ficaram oito meses. Não conseguiram encontrar mais os familiares e continuaram a viajar sozinhos. A família de Raimundo (pai de Werá), que era considerado yvyraijá (portador do bastão), passou a ser também o xe ramõi (avô), e sua esposa Benedita, a xe jary'í: eles guiaram o grupo. Trabalharam, acumularam o suficiente para passagens de ônibus até Paraíso (GO). Depois de passarem certo tempo na cidade sem conseguir trabalho, partiram para Guaraí do Norte (TO). Foram para Araguaína (TO), onde Raimundo trabalhou como coveiro. Finalmente, foram para Carmolândia (TO) e adentraram no estado de Maranhão.

Depois de passar um dia em Imperatriz, foram a Grajaú (MA), a partir do contato com outros grupos indígenas do tronco Tupi, começaram a explorar o território do entorno, e então foram para a aldeia dos Guajajara, mas como esse grupo passava por muitas necessidades com a escassez de alimentos, partiram novamente. Por volta do ano de 1976, já passando pelo reconhecimento de que eram índios, Raimundo Guarani foi pedir à Funai terras para morar. No entanto, na Funai responderam que não davam terras para ciganos, somente para índios. 
Em Grajaú, tiveram notícias que o grupo que procuravam tinha ido para Imperatriz. Seguindo esse trajeto, eles descobriram que os demais estavam próximos. Encontraram-nos morando "rio acima" de Imperatriz. Passaram dois anos vivendo com eles e então foram para Itinga do Pará, sempre com o objetivo de chegar à cidade de Belém, como destaca Jecupé (1998).

No entanto, quando chegaram a Castanhal, de acordo com Werá, o falecido nhanderú Karai Mirim parou de aparecer em sonho ao seu pai Raimundo e de mostrar o caminho que eles deveriam seguir, por isso ficaram trabalhando um bom tempo ali. Werá justifica tal fato em razão do grupo não estar mais seguindo os desígnios da divindade, das meninas estarem se relacionando com juruá (brancos), dos rapazes estarem indo em festas e bebendo. Embora essa situação ocorresse, continuaram a caminhada, chegando até as docas em Belém, prontos para embarcar para a ilha de Marajó e, momentos antes de embarcarem, encontraram um parente guarani que há muito tinha se separado deles. Este Ihes afirmou a necessidade de voltar para o Maranhão, pois ele havia tido sonhos e visões para que recomendasse ao grupo retornar. Então, mesmo alguns discordando, voltaram e foram para Santa Inês (MA), onde descobriram que haviam sido enganados pelo parente que havia se apresentado como sendo nhanderú. Retornaram novamente à aldeia dos Guajajara, vivendo por certo tempo em relativa paz, até começarem dissensos que estavam assumindo contornos de conflito.

\section{O padre e o novo reconhecimento}

Por volta de 1987, encontraram um padre que celebrava os casamentos na aldeia Guajajara e que, ao ouvi-los falar na linguagem deles, os identificou enquanto indígenas e Guarani do sul, e disse-Ihes que deveriam voltar, porque sua gente morava longe. Para atestar tal fato, o Conselho Indigenista Missionário (CIMI) financiou a viagem do filho do cacique Raimundo, João Werá Guarani, para conhecer os outros grupos indígenas no sul da América do Sul, mas principalmente os Mbyá Guarani.

Segundo os relatos de João, o grupo pensava que todos tinham saído do Paraguai e que não havia mais ninguém dos seus em outras regiões. Ao visitar algumas tekoás (lugares de morada) no Brasil, Paraguai e Argentina, ele constatou que a língua era muito parecida, se diferenciando apenas em alguns termos, e os costumes guardavam grandes semelhanças com aqueles praticados por eles, como as reuniões na opy (casa ritual) e a prática do xôndaro (dança marcial). Ao voltar, apresentou em detalhes para a comunidade tudo que havia visto e ouvido por onde andou, e o desejo dos parentes de vir conhecer quem estava há quase cem anos sem ver outro parente Guarani.

Desde o início da grande caminhada até a década de 1970, a identidade do grupo que viajava a pé, de canoa, ônibus e avião era conformada a partir da alteridade com a sociedade envolvente. Segundo 
relatos dos mais velhos, eles se reconheciam como diferentes e falantes de uma língua sem semelhanças com as de nenhum outro povo que tivessem encontrado. Sabiam perfeitamente que tinham vindo de muito longe em busca da yvy marãe'y (terra sem mal), não podendo fixar-se em terra alguma, a não ser para trabalhar e acumular dinheiro e alimentos para prosseguir a longa estrada. No percurso, eram chamados de "colombianos", "japoneses" ou "paraguaios". Passaram a se reconhecer enquanto indígenas e Guarani somente quando o padre Biale disse serem eles índios Guarani, e que havia outros do mesmo grupo nas regiões sul do Brasil.

Chegaram ao Pará em 1994, onde ficaram agregados aos Parakateje na Terra Indígena Mãe Maria, até que em 1996, com auxilio do Centro de Trabalho Indigenista (CTI), intermediado pela antropóloga Maria Inês Ladeira e pela Fundação Nacional do Índio no Pará, por meio de um projeto, conseguiram uma terra com 488 hectares onde se encontram há 19 anos, vivendo hoje dez famílias ao todo às margens do igarapé Jacundá. Até o momento, a trajetória do grupo ainda não foi registrada a contento, havendo pouquíssimas informações escritas sobre os mesmos e a memória dos mais velhos que estão vivos: pouca informação persiste. Isso ficou claro no falar dos nossos interlocutores, que até o ano de 1966, estavam juntos, e, com a morte do capitão Manoel Rodrigues, se dispersaram.

Os que estão no Mato Grosso, vivendo na cidade de Cocalinho e região, pouco sabem a respeito de onde vieram e como chegaram onde estão. Entre eles, a miscigenação com os regionais é muito forte e a linguagem é falada por poucas pessoas. Vivem na cidade e não têm uma terra demarcada. Os que estão em Xambioá (TO) vivem com os Karaja e a situação se repete, os velhos com os quais dialogamos não sabem falar a respeito da saída da Argentina, têm esparsas lembranças da caminhada, nasceram no Brasil (Goiás ou Maranhão) e afirmam que seus pais pouco falavam de sua origem. Tanto em Cocalinho como em Xambioá, a linguagem está se perdendo.

Nova Jacundá ou Tekoá Pyaú é uma terra de Mbyá, uma propriedade privada com registro lavrado em cartório. No entanto, a gestão territorial perpassa pelo uso tradicional guarani, sendo a terra de uso coletivo. Com a fixação em um lugar próprio do grupo, elementos culturais do passado apresentaram-se como forma para se reaproximar de Nhanderú Ete (nosso deus verdadeiro), considerando os ensinamentos do yvyraija (portador do pequeno bastão), Raimundo. Com sua morte no ano de 1998 em um acidente de carro, houve outra ruptura no ensino do nhandereko (modo de ser), muito embora ele tenha passado todas as instruções de como deveriam se portar após sua morte.

\section{Dança, arquitetura e paisagem}

O coral aos poucos foi se formatando, à medida que canções eram 
relembradas e outras novamente recebidas de Nhanderú Vussu (nosso deus maior), foram organizadas para constar de um novo repertório e posteriormente gravar um CD. As kiringue (meninos e meninas) ensaiam a dança e cânticos todos os dias da semana, assim como exercitam as técnicas da arte marcial xôndaro (guerreiro).

Figura 1 - Apresentação do coral no Forte do Castelo

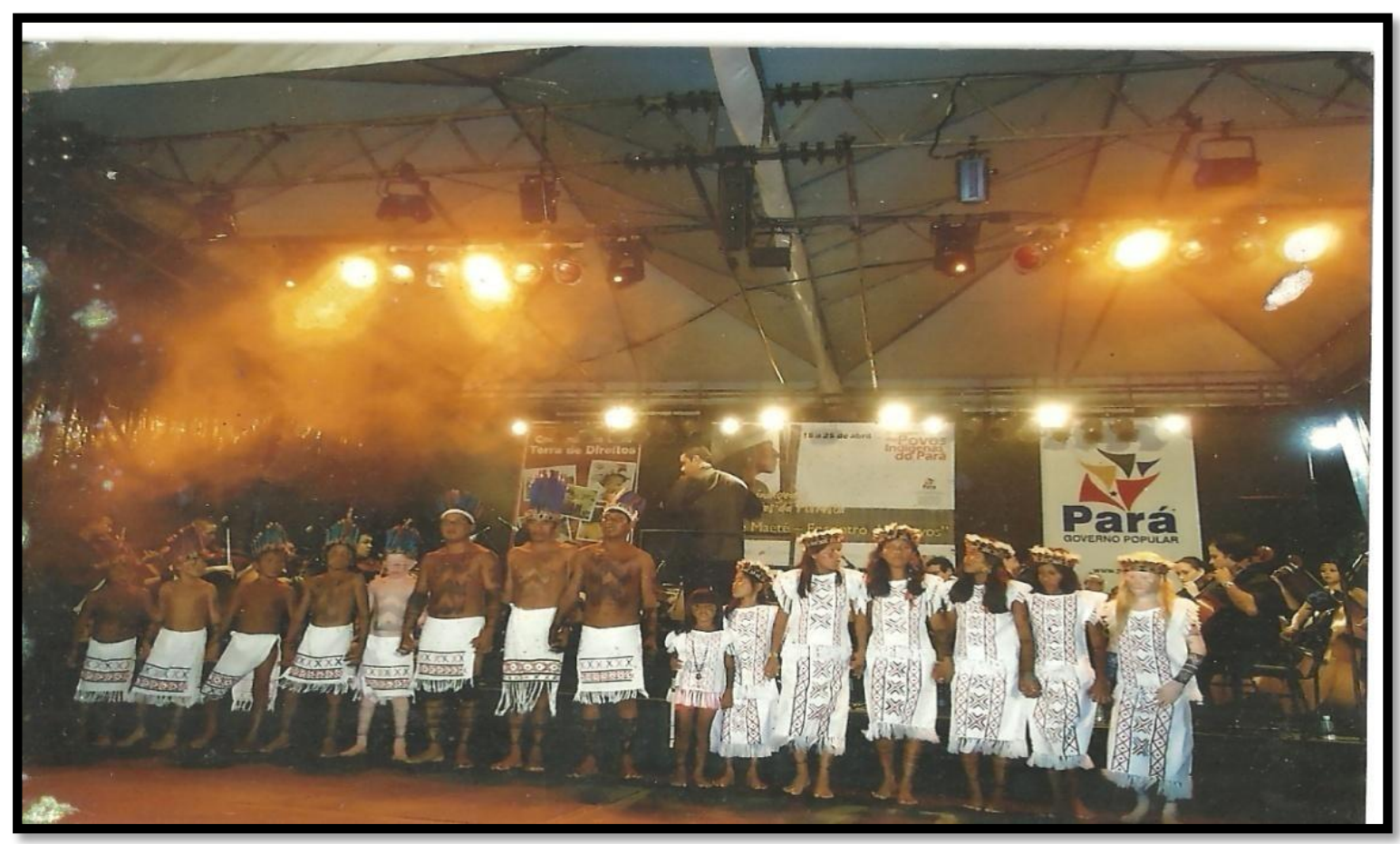

Foto: Ariana Silva, 2010.

A arquitetura das casas e a forma de construí-las foram em certa medida retomadas, muito embora empregando materiais industrializados, mesclando com madeiras lisas encontradas na floresta que compõe a terra do grupo. A construção das casas segue o padrão guarani, como encontrado nas demais aldeias, seja no Brasil ou em outros países sul-americanos.

A paisagem das construções mudou quando o governo do estado criou um projeto de habitação e construção de casas populares para povos indígenas, e um dos contemplados foi o povo Guarani da aldeia Nova Jacundá. Foram construídas 30 unidades habitacionais e, como o projeto segue um padrão, é igual em todo lugar, não considerando as especificidades habitacionais cosmológicas do povo a que é destinado ao menos foi assim com os Guarani.

Figura 2 - Paredes de palha com cobertura de telha de barro 


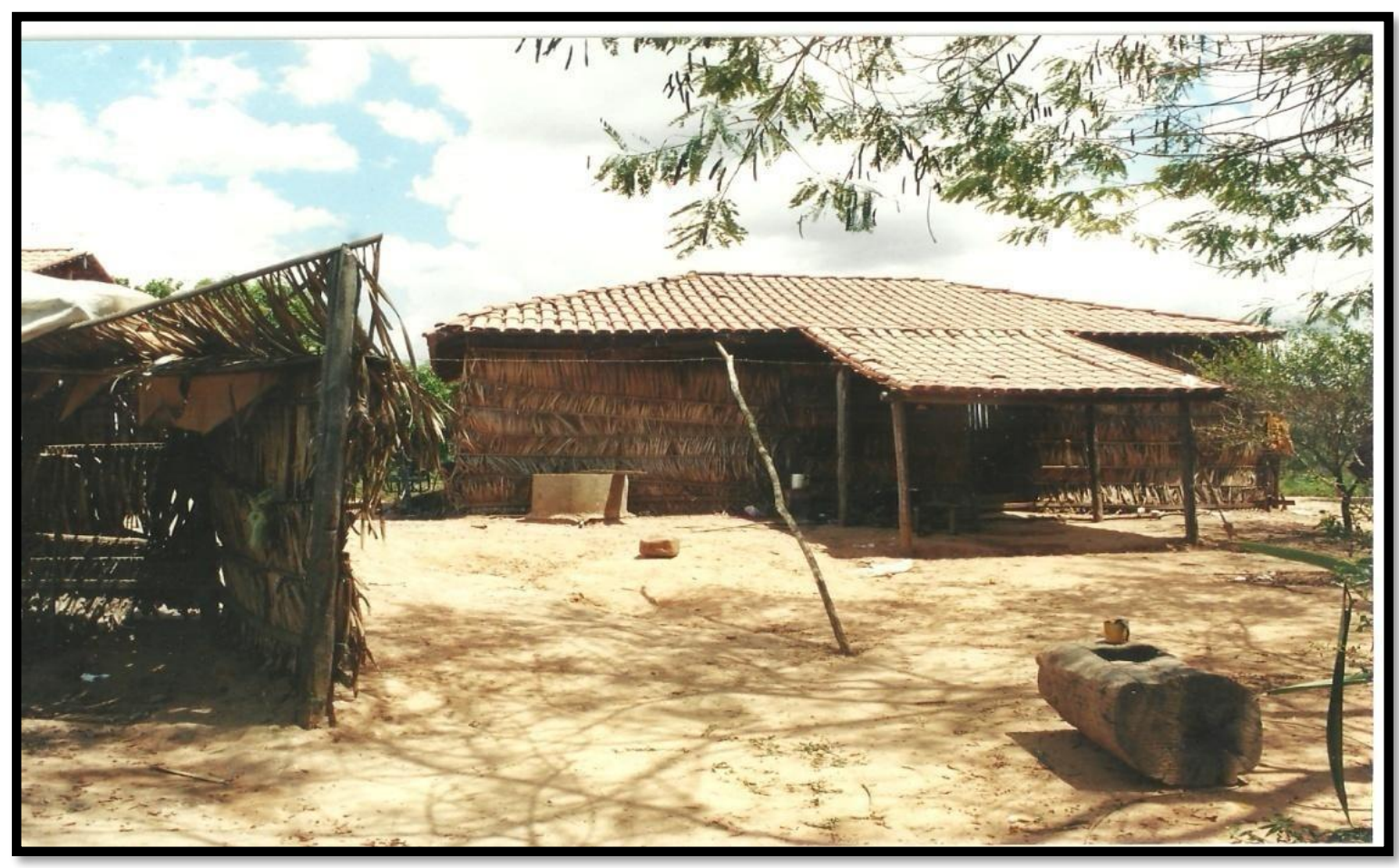

Foto: Edmar Guarani, 2007.

Logo após a entrega das casas de alvenaria, o Guarani proprietário iniciou, nos fundos ou na frente da casa recebida, a construção de edículas ou mesmo outra casa no estilo tradicional, onde a família se reúne para comer, contar casos ou planejar as atividades diárias. Pois as casas de alvenaria têm pouca claridade natural, quase nada de ventilação, são muito frias, úmidas, juntam muitas aranhas na parte interna do telhado, assim como outros animais que causam doenças, alergias e queimaduras. No período do inverno, com as chuvas intensas, respinga muito ou surgem goteiras, e o mofo toma conta do que se tem dentro de casa.

Muito embora se tente melhorar a construção, ela apresenta muitas imperfeições na sua finalização. A cada etapa da construção, vinha uma equipe nova e por vezes destruía a que a anterior havia feito, e então reconstruía. Como a construção se desenvolvia a passos lentos e o prazo estava expirando, aceleraram as atividades, e assim o acabamento de muitas casas ficaou a desejar. Porém, como diziam os pedreiros e serventes, "é pra índio, não precisa caprichá, eles nunca tiveram nada assim". Dito isso, os Mbyá Guarani não se lembram de ter visto qualquer arquiteto ou engenheiro vistoriando as obras.

Figura 3 - Alvenaria em contraste com a opy 


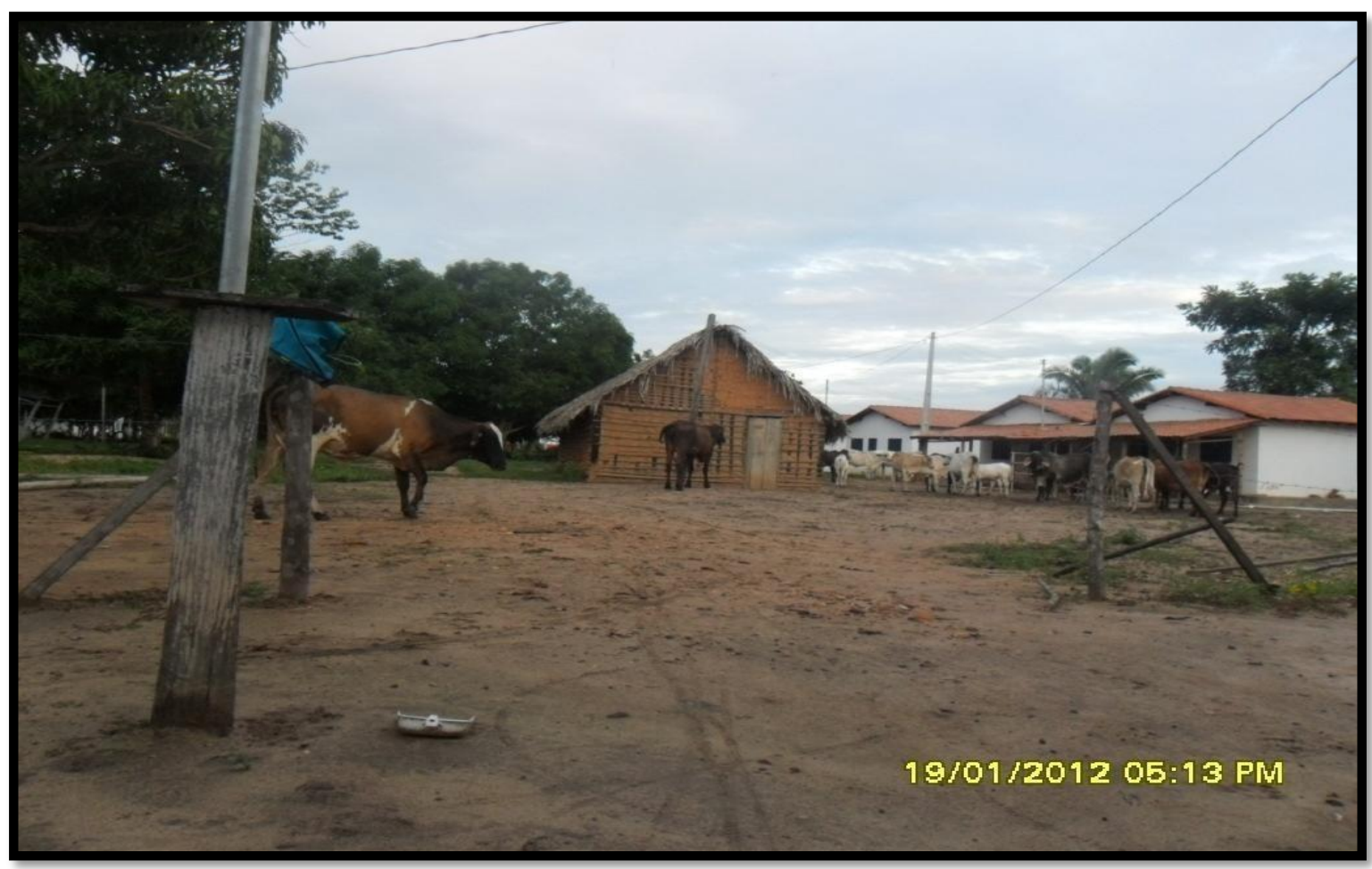

Foto: Amirele Yvy Poty î, 2012.

\section{A cerimônia}

A opy foi construída e algumas cerimônias retomadas quase que cotidianamente. Muito embora não tenha a pessoa do nhanderú (orientador espiritual), somente oporaívas (cantores), os ensinamentos do modo tradicional de ser perpetuam-se. Percebemos essa constância nos mais velhos; os mais jovens parecem não ter interesse nesses aspectos da cultura e da religião. Talvez esteja ocorrendo um choque de gerações devido a influencias externas e/ou pelo fato de não mais caminharem: a unidade esvai-se. Ressente-se também o fato de que muitas informações não são do conhecimento da comunidade, pois foram enterradas com os mais antigos e ninguém mais as sabe contar.

As cerimônias acontecem quase todas as tardes, ao pôr-do-sol. Os xôndaro (guerreiros) tocam o Angu"a pú (tambor) e todos se dirigem para o pátio na frente da casa da jary'ì Benedita; os que cantam no coral são os que mais se apressam, pois sem eles nada se sucede. Ensaiam os mboraei (cânticos) e jerojy (dança), e, encerrada essa parte, vão para casa tomar banho e jantar, para retornar à opy (casa ritual), que já encontram varrida e com o chão umedecido, para não levantar poeira.

Ao entrar, procuram onde se sentar e duas das meninas presentes recolhem os petynguas (cachimbos) e os enchem de pety (fumo), acendendo-os, para em seguida entregá-los aos homens. Então um dos 
homens se levanta e anda em círculos, esfumaçando o ambiente e tudo que há no interior da opy'ì (casinha ritual). Em seguida, as pessoas são fumegadas no centro da cabeça e recebem a saudação guarani. Os demais que estão com cachimbo podem seguir os mesmos passos: ao final tudo e todos são esfumaçados por quem tiver em mãos um petynguá (cachimbo), e quando tudo já estiver sido esfumaçado e as pessoas saudadas, um a um os homens retornam aos seus lugares e os petynguá são recarregados. Após isso, um dos oporaíva (cantores) se levanta, pega o mbaraká (chocalho) e começa a sua nhe'engaraì, acompanhado pelos demais com ravé (violino), mbaraka mirim (violão de cinco cordas), angu'a pú (tambor) e takuapu (bastões de ritmo feitos de bambu). Todos cantam, inclusive as crianças, e o acompanhamento se dá em partes, de forma alternada. Usualmente, quem pretende ir para a opy (casa ritual), deve se dirigir a ela antes do pôr-do-sol, organizando-se em fila única: primeiro os homens e em seguida as mulheres, então se inicia o ritual que permite a entrada no recinto. O opyguá (orientador espiritual) posiciona-se em frente à porta, enquanto os que estão em fila devem contornar a opy duas vezes, e então se pronuncia a saudação usual: aguyjevete, e entram.

Assim que todos entram, a porta é fechada e lá dentro iniciam-se os primeiros rituais; os que chegam atrasados devem esperar o momento em que o xondaro a abre novamente, e assim têm um instante em que podem entrar. Embora seja usual, não é regra geral este procedimento.

\section{Figura 4 - Opy no centro do tekoá}

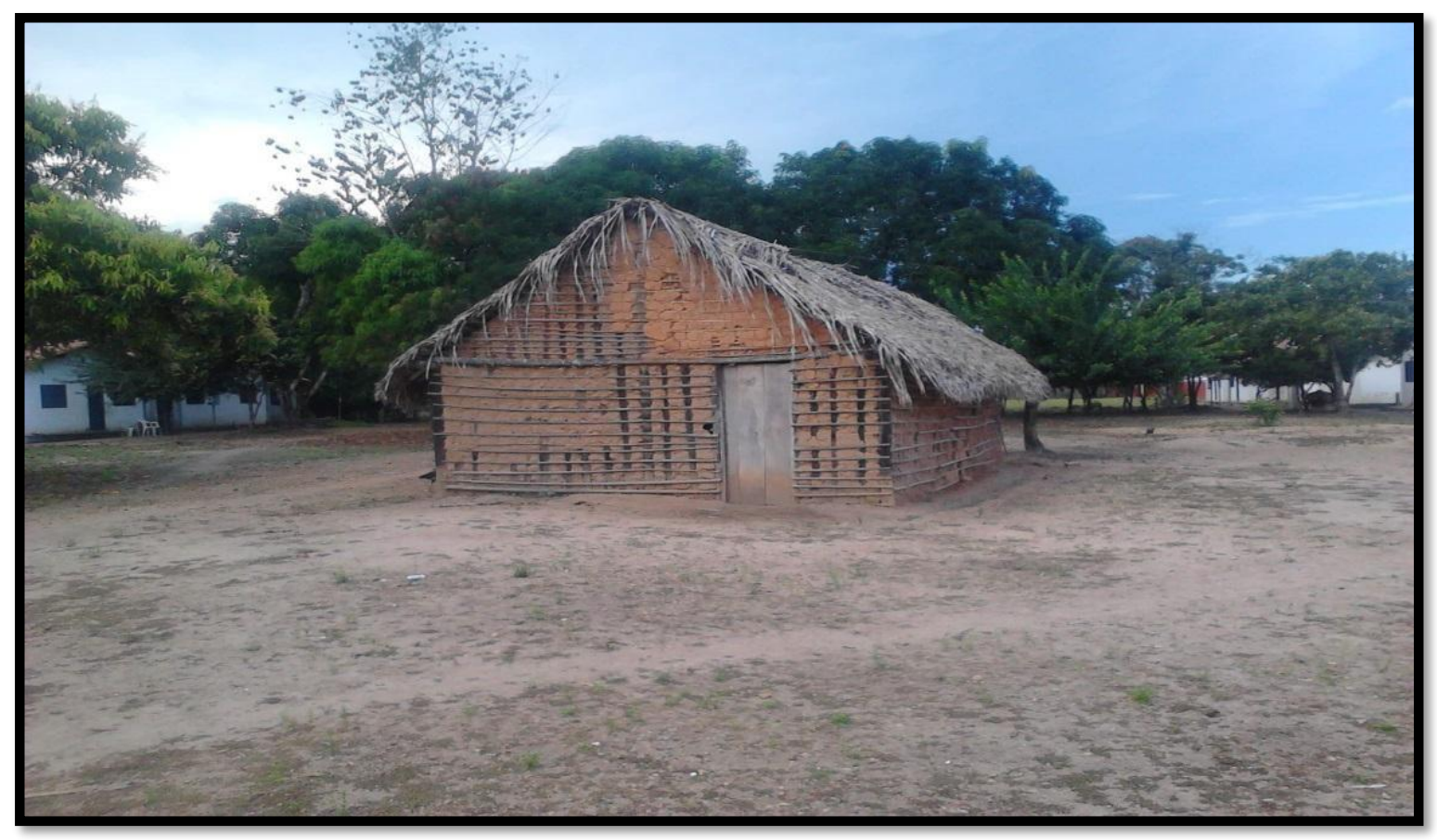

Foto: Almires Martins Machado, 2013.

\section{Objetos sagrados e roças}


Os instrumentos, como mbaraká mirim (violão), ravé (rabeca, violino), mbaraká (chocalhos), foram adquiridos ou confeccionados pelo próprio grupo. Os hábitos alimentares e as técnicas de preparação das roças foram formatados a partir de suas memórias alimentares.

As roxaro (roças) são geralmente plantadas nas clareiras abertas na mata, depois de terem sido feitas a roçada, a derrubada, a queimada, e em seguida, a coivara. Ao redor fica uma parede de proteção que é a própria floresta, criando sombra, frescor necessário à conservação prolongada da umidade no solo. Entre os tocos de arvores que não pegam fogo e cinzas acumuladas pela queima, a família se reúne e inicia o trabalho de plantio. É usada a técnica de plantio de múltiplas culturas, ou consorciadas: avati (milho), kumandá (feijão), mandió (mandioca), jety (batata-doce), andaí (abóbora), xãjau (melancia), paková (banana), takuáre'e (cana-de-açúcar), manduví (amendoim), entre outros. Cada família tem a sua própria roxaro e, no momento de plantar, pode ser feito um mutirão ou paga-se para um ou vários diaristas para fazer a broca da mata. A área plantada varia muito de tamanho e está relacionada com o número de pessoas da família, na media fica em torno de oito linhas ou dois hectares, mas há os que preparam dezesseis linhas ou quatro hectares. Plantar não é somente para consumo, mas para vender o excedente e obter dinheiro.

Figura 5 - Roça, com casa de descanso e armazenar produtos

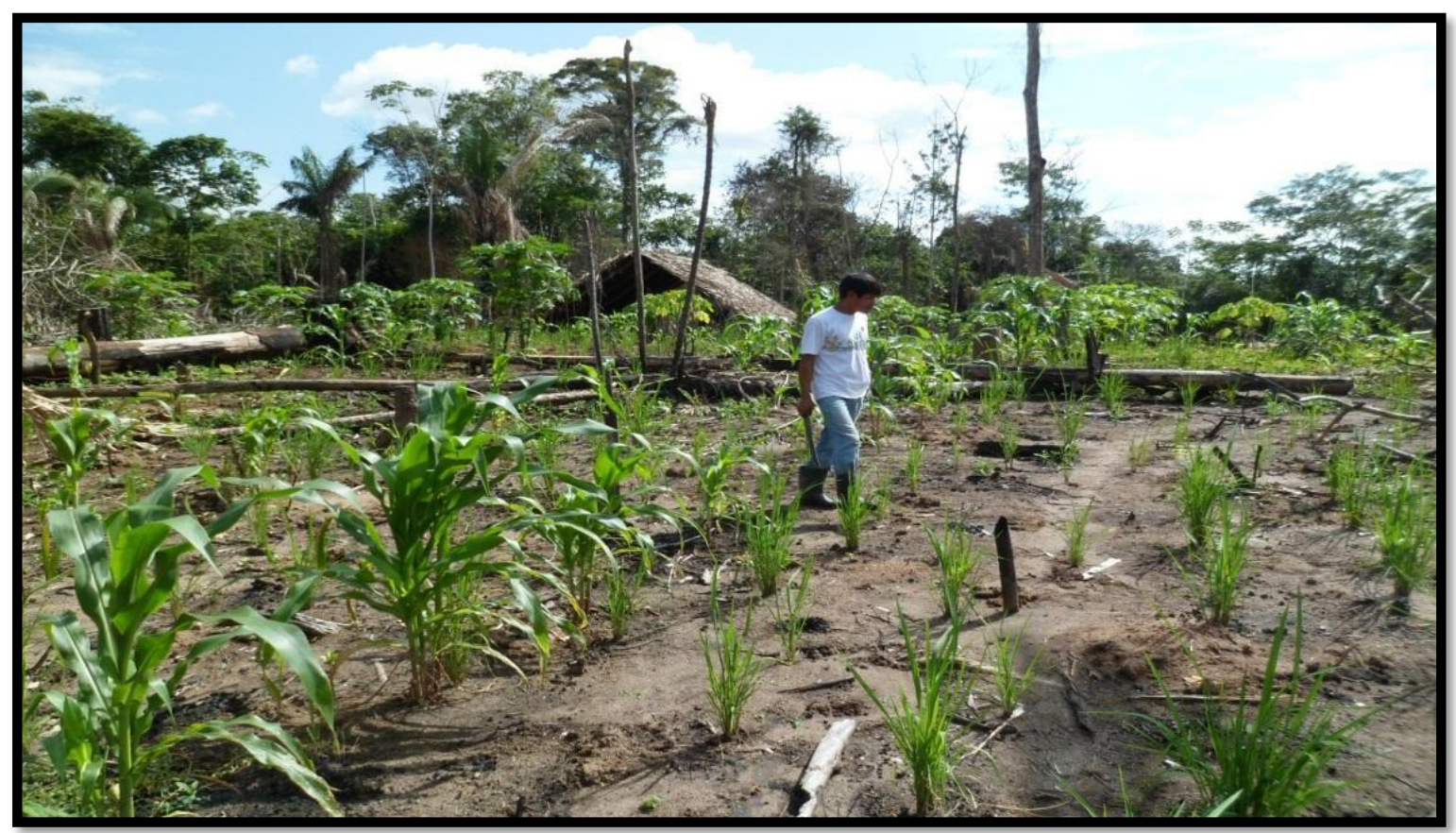

Foto: Almires Martins Machado, 2013. 


\section{A arte e educação guarani mbyá}

Por fim, o artesanato tradicional foi reintroduzido, ensinado nas oficinas por artesãos Guarani Mbyá da própria comunidade ou vindos de outras comunidades. As técnicas ensinadas foram as de confeccionar colares, peneiras, cestas, esteiras, com as mais diversas formas de caracterizá-los com o grafismo guarani. Aprenderam a coletar os materiais na floresta e o modo correto de preparar e cortar os materiais, assim como qual a lua própria para tal. Alguns materiais não são encontrados nas matas do tekoá (lugar de morar), precisam ser obtidas em outras aldeias.

Figuras 6 - Aula de artesanato tradicional

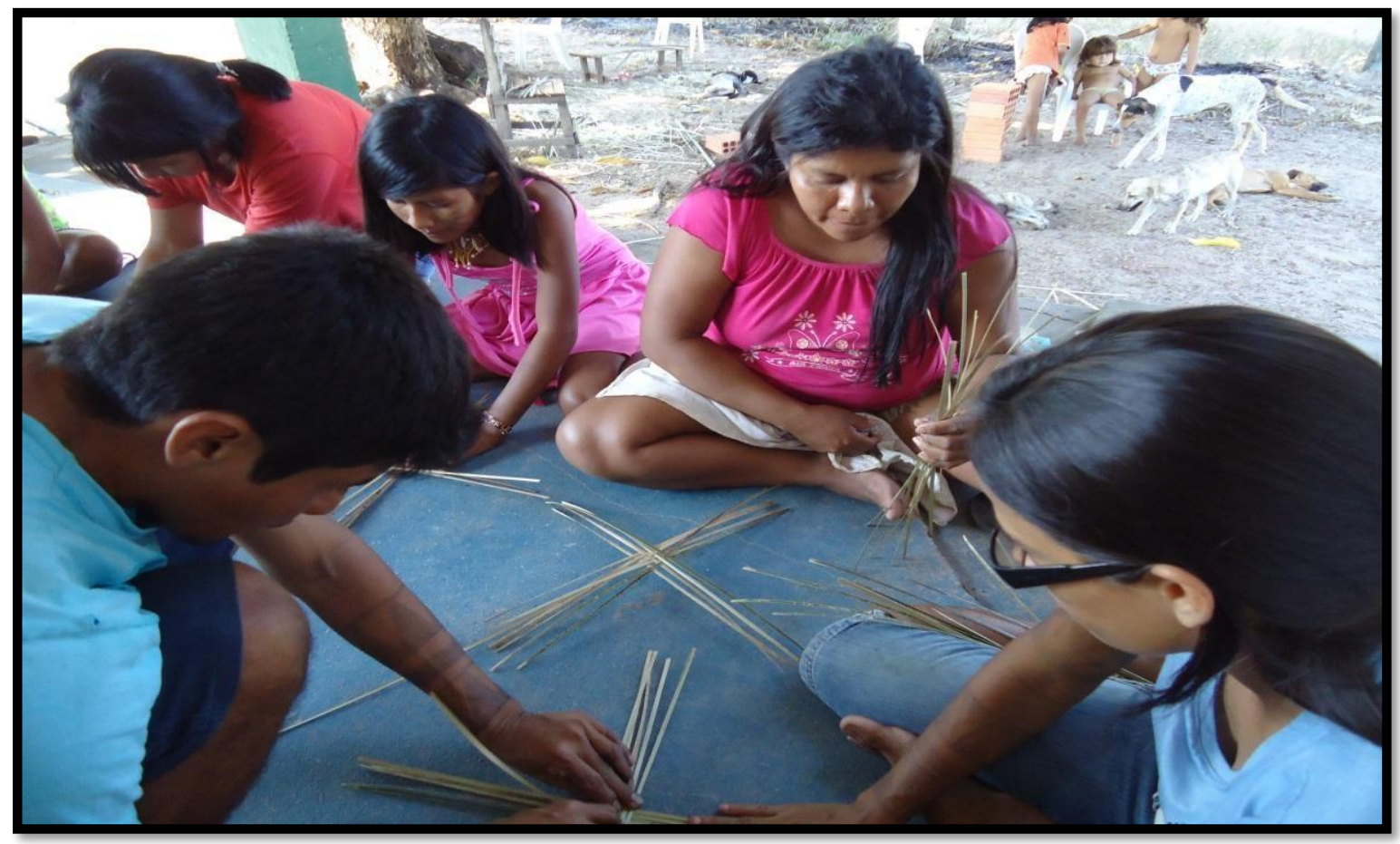

Foto: Leonardo Guarani, 2010.

O espaço da escola abarca outros sentidos, como o da sociabilidade, pois na sua área externa, no alpendre ou debaixo da mangueira, como se vê na imagem acima, ocorrem oficinas de artesanato: atividades de conhecimento tradicional migraram para esse espaço, guaranizando a escola, como afirmam que ela "é coisa de juruá". É nesse espaço que está sendo valorizada a cultura; na sala, de aula é potencializado o ser Guarani a partir do nhandereko'a (nosso modo de ser). É nesse espaço que ocorrem as sessões de grafismo corporal, embora os mais velhos afirmem que os Guarani não usam pintura corporal, a não ser em ocasiões especiais.

A escola foi construída e entregue no ano de 2003 , recebendo o 
nome de Kariwassu Guarani, em homenagem ao yvyraijá (portador do pequeno bastão de madeira) Raimundo Guarani, xe ramõi (avô) do grupo, que faleceu em 1998, vítima de acidente de trânsito. É uma escola que pertence ao município de Jacundá, embora a aldeia esteja no município de Rondom do Pará. Atende alunos do ensino fundamental, e os que querem dar continuidade aos estudos no ensino médio têm de ir para a cidade de Jacundá, que dista $50 \mathrm{~km}$ da aldeia. O transporte escolar nem sempre pode ir até onde o estudante está, passando apenas perto da aldeia, e no inverno (período das chuvas), por vezes nem adentra a vicinal, ficando nas proximidades da PA-150. A escola ainda não tem constituído formalmente seu Projeto Político Pedagógico (PPP), pauta-se por educação bilíngue (guarani mbyá e português), comporta ações de preservação cultural e conquista de espaços de mobilidade política, por meio do aprendizado de linguagens da sociedade nacional em busca de garantir os direitos e interesses da comunidade.

Figura 7 - Escola Kariwassu Guarani

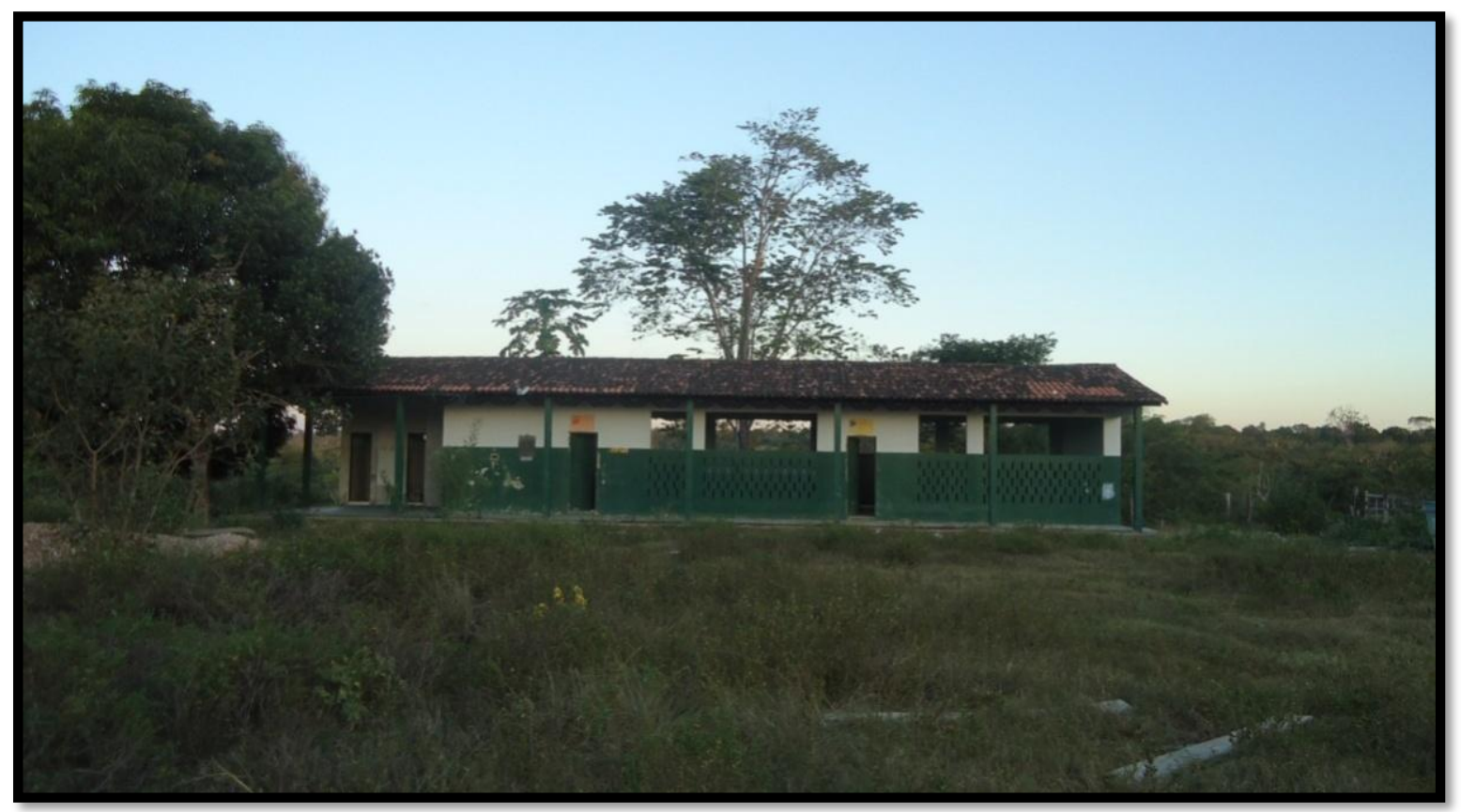

Ariana Silva, 2010.

A respeito da escola, discorre Werá (relato de 2015):

Esse lado eu digo que a escola na aldeia, ele tem que ser respeitado o dia de acordo com os índios, com a comunidade eu acho porque não é ainda, não respeita a nossa vontade aqui dentro, eles marca assim um dia que nós tem que ta estudando direto, quando não manda um papel de Jacundá dizendo como pode fazer a merenda, não é nós que vamos escolher o que vamos fazer 
amanhã pros meninos, o que que os meninos quer comer. Então tudo já vem marcadinho no papel, tal dia esse aqui tal dia é esse, tal dia é esse aí. A gente faz isso aqui, aí os meninos não comem, aí perde. Então eu queria que a gente mesmo fizesse né, o que que a gente vai dar naquele dia pros meninos, fazer não aquilo escrito. Aqui é é o que os meninos vão comer, então vamos marcar aqui então esse que eu queria que todo mundo respeitasse, como é nosso jeito na aldeia.

A escola faz parte do cenário da aldeia, mas ela não é parte integrante da vida guarani. Embora hoje o desejo seja o de estudar, obter o diploma num curso técnico ou mesmo uma graduação, a escola ainda não tem papel relevante na vida das crianças, apesar de ser um espaço de "transmissão" de conhecimentos, algo como a opy (casa ritual), com a diferença que nela não há belas palavras, mas conversas que causam fastio com muita rapidez. Acreditamos que talvez seja por não ser respeitado o tempo de aprendizagem de cada um, especialmente considerando que os ensinamentos não são de origem guarani, não são narrados com a performance dos mais velhos. Os professores não conseguem seduzir o estudante. As aulas mais interessantes, movimentadas, alegres, descontraídas, são as de cultura e linguagem. Embora as crianças entendam a linguagem, poucas se arriscam a pronunciar, falar. O esforço das professoras Maria Guarani e Edmar Guarani, assim como os demais que vez ou outra participam, é para que as kiringue (crianças) sejam em breve fluentes.

Pensando nisso, foi elaborado e impresso um livro sobre o modo de vida mbyá de Nova Jacundá. Como se vê na imagem, o momento mais aguardado é o de ir ao igarapé se refrescar. Tentamos nas próximas linhas delinear rapidamente o problema vivido na escola, considerando a observação de Werá.

Muito antes de o não-indígena aportar em nossas terras e trazer com ele a escola, todos os povos indígenas tinham por muito certo a sua pedagogia e metodologia de ensino, sendo o princípio educar para ter um adulto consciente de seus deveres para com o seu povo, sua família e principalmente o respeito às narrativas (mitos) e à natureza. Desde tenra idade, as crianças iniciavam o seu aprendizado com todos do povo ao qual pertenciam, aprendiam por imitação; todos os momentos de aprendizagem consistiam em aulas teórico-práticas. Assim era o cotidiano dos meninos, todos os adultos ensinavam-lhes, eles não eram filhos de tal indígena, mas filhos da comunidade.

A sala de aula era a grande e exuberante mãe natureza, as lições sobre astrologia, física, biologia, geografia, história, filosofia e botânica eram ensinadas nas caçadas, pescarias, excursões de coleta de frutas e raízes ou de exploração do território pertencente àquele povo. À noite, as lições continuavam ao redor da fogueira ou nas opy (casas rituais), a cada momento durante as festas e rituais. Da mesma forma, as meninas realizavam o seu aprendizado com as mulheres da comunidade: eram 
filhas de muitas mães, ensinadas dos deveres e obrigações de futuras mulheres e esposas, principalmente do seu papel político na sustentação das bases familiares que compunham os tekoás guarani, assim como a sua participação nos rituais religiosos. A premissa desse aprendizado era tornar a criança um adulto capaz de ser independente e obter o seu sustento sem ajuda de terceiros, trabalhar para o bem comum de sua comunidade e estar pronto para o casamento no final do aprendizado, que se dava com rito de iniciação, quase sempre coincidindo com o início da puberdade. Após iniciado, passa a pertencer ao círculo dos adultos, por volta dos doze ou treze anos.

Figura 8 - Crianças se banhando no igarapé Jacundá

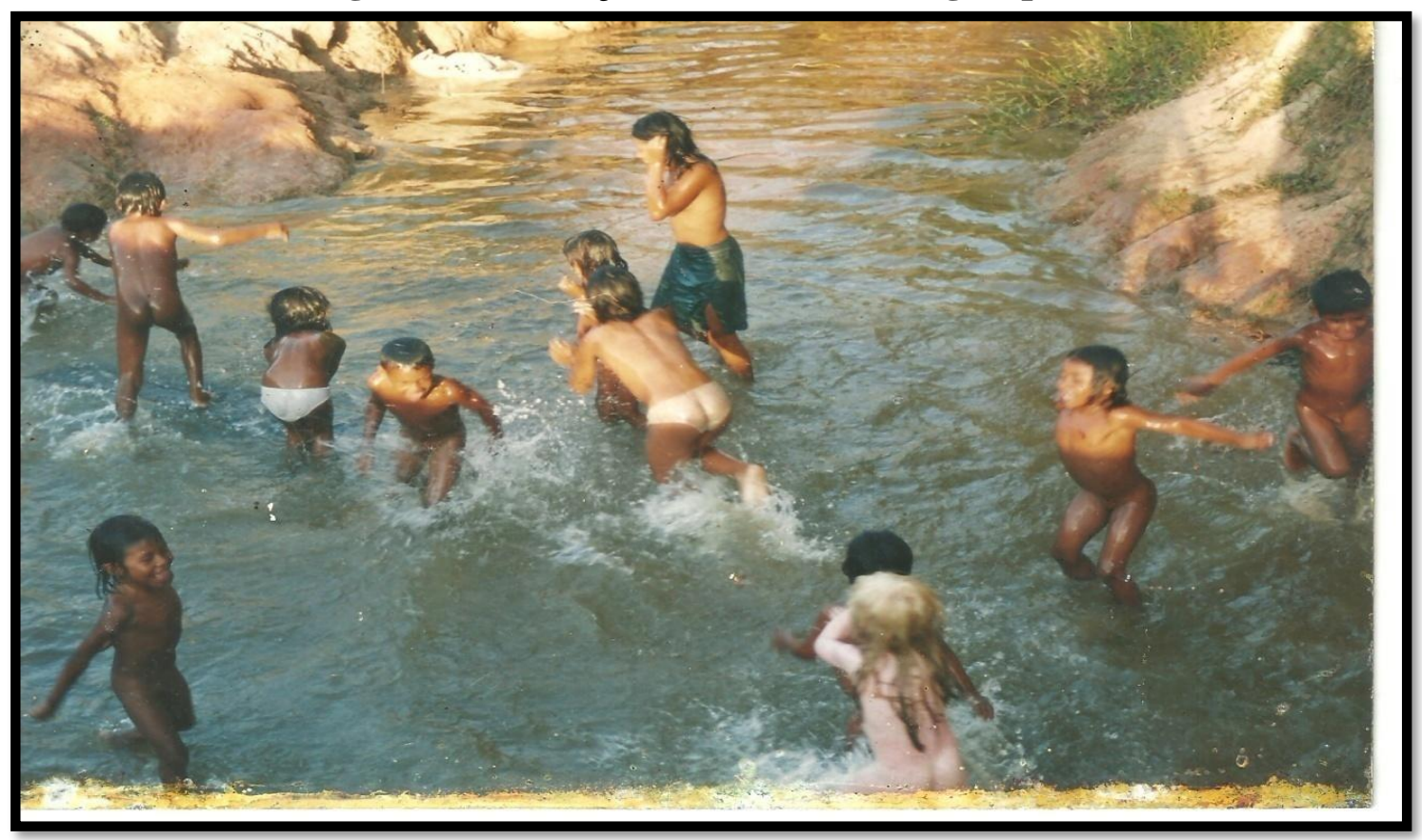

Foto: Edmar Guarani, 2005.

Toda a educação indígena é direcionada para a convivência em um espaço de igualdade: não se exclui ninguém da vida social, porque se busca potencializar nas práticas sociais as bases de uma sociabilidade na qual as relações sociais expressem o reconhecimento do indivíduo na condição de sujeito de direito no âmbito da comunidade, portanto, de igual. É inerente ao processo de reconhecimento da trajetória de homens e mulheres como avaetes (idôneo, verdadeiro) serem portadores do poder da palavra.

\section{A chegada dos europeus}

O europeu chega e com ele o seu etnocentrismo e a escola, desprezando todos os métodos de educação indígena. $O$ recém-chegado via no indígena um bárbaro, ignorante, inculto, chamando-o de "negro da 
terra", "selvagem", a quem fez guerra por o mesmo não concordar com os seus métodos "civilizados" de tratar o outro. Matou, exterminou dezenas de milhares em nome da civilização, para ser dono, senhor dos sertões e do que havia neles, inclusos os habitantes.

Com o passar do tempo, surgiram escolas nas aldeias ou nos redutos onde se amontoavam os indígenas mansos, amigos dos portugueses, cujos filhos participavam da escola, responsabilidade da Igreja Católica no período colonial, sendo a mesma uma imposição aos povos indígenas que dela participavam. A escola para indígenas, durante o período colonial, primava pela conversão religiosa e o uso de sua mão de obra para todo tipo de trabalho, além da função de "integrar", entendendo que os mesmos eram destituídos de cultura. Essa foi a ferramenta eficiente de destruição das culturas indígenas, significando a destruição das formas de organização social, regras de parentesco e das religiões indígenas predominantes naquelas comunidades, desprezando a operabilidade, praticidade e a veracidade de suas instituições milenares, baseadas principalmente na cosmologia.

Essa é a chamada primeira fase da história da educação escolar indígena no Brasil (colonial), fase da educação religiosa. A segunda fase apresenta-se com o advento da criação do Serviço de Proteção aos Índios (SPI), em 1910, e posteriormente com a sua substituição, em 1967, pela atual Funai. Pode-se inferir que a terceira fase começa a delinear-se na década de 70, conforme Matos e Monte (2006, p. 72):

De 1500 para cá, é possível perceber que as preocupações com a educação escolar para os índios ganharam contornos mais específicos a partir da década de 1970, momento em que grupos sociais, formados por não-índios, iniciam um processo de assessoria a algumas comunidades indigenas, em busca de "um modelo de escola mais respeitoso à diversidade e aos direitos coletivos assegurados mais tarde na Constituição brasileira.

E a quarta fase se inicia na década de 90. Em 1991 promulgou-se o decreto que delegou ao Ministério da Educação a coordenação de políticas públicas e ações em prol da educação escolar indígena, substituindo a Funai. É o inicio do novo processo de políticas públicas para a educação escolar indígena, redundando na Lei de Diretrizes e Bases para a Educação Nacional (LDB), em 1996; Plano Nacional de Educação, em 2001; e no Referencial Nacional para as Escolas Indígenas (RCNEI), em 1998. A Lei no 9394/1996 dedica dois artigos no título de Disposições Gerais à educação escolar indígena.

O Artigo 78 prevê que o sistema de ensino da União desenvolva sistemas integrados de ensino e pesquisa para a oferta de educação escolar bilíngue e intercultural aos povos indígenas, oferecendo lastro à existência de subsistema de ensino voltado exclusivamente para a educação indígena, devendo ter uma estrutura diferente da vigente nas 
escolas fora das comunidades indígenas. A consequência imediata da Lei de Diretrizes e Bases da Educação Nacional (LDB) concretizou-se na elaboração do Plano Nacional de Educação, fundamentando-se nas previsões constitucionais, assegurando o direito à educação escolar indígena, previstos nos artigo $5{ }^{\circ}$ caput, CF $/ 88 ; 4^{\circ}$, IV; $205 ; 206$, I; 208, I e IV; respectivamente: a igualdade de todos perante a lei; direito de todos a não serem discriminados; à educação; à igualdade de condições; ao acesso e permanência na escola; ao ensino fundamental obrigatório e gratuito, e ao acesso aos níveis mais elevados de ensino, pesquisa e criação.

Esse novo despertar nasceu na proposição da Constituinte de 1988, que previu as nuances da educação indígena proposta a partir de novo olhar, considerando a valorização do ser indígena e não mais sua integração à sociedade nacional. Com as normas constitucionais, o indígena deve ser ele mesmo, quem sempre foi: um individuo com usos, costumes e dotado de cosmovisão diferente. Os reflexos da nova forma de conceber a escola, não mais uma escola para indígenas e sim uma escola indígena, não significa radicalização, pois muita coisa do que pertence à escola formal não-indígena pode ser aproveitado ou reinterpretado ao paradigma pedagógico indígena, que faz o papel de interlocutor no estabelecimento do diálogo nessa transição.

\section{Referências bibliográficas}

BRASIL/MEC. Lei no . 9.394, de 20 de dezembro de 1996. Lei de Diretrizes e Bases da Educação Nacional. Brasília, 1996.

BRASIL. Referencial Curricular Nacional Para as Escolas Indígenas, (RCNEI), 1998.

BRASIL. Lei n. 10.172, de 9/1/2001. Estabelece o Plano Nacional de Educação. Diário Oficial da União, Brasília, 2001.

CADOGAN, León. Ayvu Rapyta: textos míticos de los Mbyá-Guarani del Guairá. Asunción> Fundación León Cadogan, Ceaduc/Cepag, [1959]1992.

JECUPÉ, Kaka Werá. A terra dos mil povos: história indígena brasileira contada por um índio. São Paulo: Peirópolis, 1998.

MATOS, K. G.; MONTE, N. L. O estado da arte da formação de professores indígenas no Brasil. In: GRUPIONI, L. D. B. (org.). Formação de professores indígenas: repensando trajetórias. Brasília: MEC/SEC/AD, 2006. p. 69-114.

MONTEIRO, John Manoel. Os Guaranis e a historia do Brasil meridional: séculos 
XVI - XVII. In: CARNEIRO DA CUNHA, Manoela (org.). História dos índios no Brasil. São Paulo: Companhia das Letras, 1998.

SUSNIK, B. Los aborígenes del Paraguay II: etnohistória de los Guaraníes, época colonial. Assunción: Museu Etnográfico Andrés Barbero, 1980.

Recebido em: 13/06/2018 * Aprovado em: 12/12/2018 * Publicado em: 27/06/2019 